\title{
EDUCAÇÃO AMBIENTAL E SUAS PRÁTICAS COMO EXERCÍCIO DA CIDADANIA NA ESCOLA BÁSICA
}

\author{
ENVIRONMENTAL EDUCATION AND ITS PRACTICES AS AN EXERCISE OF \\ CITIZENSHIP IN THE BASIC SCHOOL
}

\section{LA EDUCACIÓN AMBIENTAL Y SUS PRÁCTICAS COMO EJERCICIO DE CIUDADANÍAENLAESCUELA BÁSICA}

Iara Maria Soares Costa da Silveira ${ }^{1}$ https://orcid.org/0000-0001-9898-0294

Túlio de Oliveira Ruas ${ }^{2}$ https://orcid.org/0000-0001-9760-9637

Nayara Ferreira Elias ${ }^{3}$ https://orcid.org/0000-0002-9867-0381

\footnotetext{
${ }^{1}$ Doutora em Geografia - UFU. Professora do Departamento de Geociências - Universidade Estadual de Montes Claros. E-mail: yara.mariasilveira@gmail.com

${ }^{2}$ Graduado em Geografia - Universidade Estadual de Montes Claros. E-mail: thulio72@ hotmail.com

${ }^{3}$ Graduada em Geografia - Universidade Estadual de Montes Claros. E-mail: naya1661@ yahoo.com.br
}

\section{RESUMO}

A Educação Ambiental é de suma importância para a sociedade, sobretudo no que diz respeito à sensibilização dos indivíduos em relação ao Meio no qual estão inseridos, visando sempre uma excelente qualidade de vida sem prejudicar o meio ambiente. Para tanto, essa abordagem no âmbito educacional deve ser implementada por meio da dialética e da interdisciplinaridade, com o intuito de estabelecer relações entre a utilização dos recursos naturais e o equilíbrio entre o homem e o meio ambiente. Sendo assim, este estudo analisou a importância da abordagem da Educação Ambiental na Educação Básica, tais como os desafios enfrentados por parte dos educadores na prática escolar para o efetivo exercício da cidadania. Entre os dificultadores observados a maior ênfase esteve voltada para a limitação dos recursos pedagógicos e financeiros, materiais metodológicos auxiliadores, escassez de capacitação de docentes para abordar as diversas particularidades e especificidades da temática, defasagens de conteúdo para as práticas interdisciplinares, resistência ao trabalho interdisciplinar e insegurança nas abordagens ambientais. Estes motivos reduzem os avanços no contexto escolar, uma vez que possuem grande responsabilidade na formação de cidadãos sensíveis e participativos, capazes de propagar conhecimentos e desenvolver ações positivas para a sociedade.

Palavras-chave: Meio ambiente; Ensino; Interdisciplinaridade. 


\begin{abstract}
Environmental Education is of paramount importance to society, especially with regard to raising awareness of individuals in relation to the environment in which they operate, always aiming at an excellent quality of life without harming the environment. Therefore, this approachin the educational field must be implemented through dialectics and interdisciplinarity, with the aim of establishing relationships between the use of natural resources and the balance between man and the environment. Therefore, this study analyzed the importance of the Environmental Education approach in Basic Education, such as the challenges faced by educators in school practice for the effective exercise of citizenship. Among the observed difficulties, the greatest emphasis was on limiting pedagogical and financial resources, assisting methodological materials, shortage of teacher training to address the diverse peculiarities and specificities of the theme, content gaps for interdisciplinary practices, resistance to interdisciplinary work and insecurity in environmental approaches. These reasons reduce advances in the school context, since they have a great responsibility in the formation of sensitive and participative citizens, capable of spreading knowledge and developing positive actions for society.
\end{abstract}

Keywords: Environment. Awareness. Interdisciplinarity.

\title{
RESUMEN
}

La Educación Ambiental es de suma importancia para la sociedad, especialmente em lo que respecta a la sensibilización de las personas em relaciónconel entorno enel que se desenvuelven, buscando siempre una excelente calidad de vida sinda ñar el medio ambiente. Por tanto, este enfoque enel campo educativo debe implementarse a través de la dialéctica y la interdisciplinariedad, conel objetivo de establecer relaciones entre el uso de los recursos naturales y elequilibrio entre el hombre y el medio ambiente. Por ello, este estudioanalizólaimportanciadel enfoque de Educación Ambiental em la Educación Básica, como los desafíos que enfrentanlos educadores enlapráctica escolar para elejercicio efectivo de la ciudadanía. Entre lasdificultades observadas, elmayorénfasisestuvoenlalimitación de recursos pedagógicos y financieros, materiales metodológicos auxiliares, escasez de formación docente para abordar las diversas peculiaridades y especificidades del tema, vacíos de contenido para prácticas interdisciplinarias, resistencia al trabajo interdisciplinario e inseguridaden enfoques ambientales. Estas razones reducenlos avances enel contexto escolar, ya que tienen una gran responsabilidade em la formación de ciudadanos sensibles y participativos, capaces de difundir conocimientos y desarrollaracciones positivas para la sociedad.

Palabras clave: Medio Ambiente. Enseñando. Interdisciplinariedad.

\section{INTRODUÇÃO}

A Educação Ambiental é trabalhada nas instituições de ensino com o intuito de formar indivíduos cientes e preocupados com o Meio em que vivem; que não apenas percebam os passivos ambientais presentes, mas que busquem a preservação, conservação dos recursos naturais e a sustentabilidade no decorrer de toda a sua formação como cidadão consciente de suas ações. Segundo o Ministério do Meio Ambiente (Lei no 9795/1999, Art 1º: “A Educação Ambiental, é um processo por meio do qual o indivíduo e a coletividade constroem valores sociais, conhecimentos, habilidades, atividades e competências voltadas para a conservação do meio ambiente." Desse modo, a Educação Ambiental no contexto escolar é uma das 
estratégias que busca contribuir na formação de indivíduos críticos, sobretudo em relação à sua realidade.

A Educação Ambiental, hoje, apresenta-se como uma das estratégias que pode contribuir na formação de cidadãos ativos em relação a sua realidade. O processo de aprendizagem que a envolve deve ser centrado no aluno, gradativo, contínuo e respeitador de sua cultura e sociedade. Deve ser um processo crítico, criativo e político, com a preocupação de construir conhecimentos a partir da discussão e envolvimento com os processos avaliativos dos problemas comunitários, assim como do olhar observador dos estudantes que, como protagonistas exercem um importante papel de sensibilização social por meio de uma realidade individual e coletiva na comunidade em que vivem, fruto das percepções e vivências apreendidas cotidianamente, fator que gera resultados positivos a curto e longo prazo.

O envolvimento da escola nas práticas educativas para suprir as reflexões sobre as relações dos seres vivos entre si, do ser humano com ele mesmo e do ser humano com a sociedade é condição imprescindível para que a Educação Ambiental ocorra. Dentro desse contexto, destaca-se a escola, como um espaço privilegiado na implementação de atividades que propiciem essa reflexão, com ações orientadas em processos de participação que induzam à autoconfiança, às atitudes positivas e ao comprometimento pessoal com a proteção ambiental implementados de modo interdisciplinar.

O objetivo central deste trabalho é descrever sobre a importância do ensino e das práticas da Educação Ambiental na Educação Básica voltadas ao Ensino Fundamental que é composto pelo sexto, sétimo, oitavo e nono ano, aspirando à fixação dos conteúdos interligados a relação sociedade/natureza, tendo como premissa um trabalho de campo de reflorestamento da mata ciliar do Rio São Lourenço. Este trabalho foi considerado relevante para a formação de uma sociedade consciente, crítica e participativa nos processos sociais.

O Trabalho de Campo envolveu parte da mata ciliar do Rio São Lourenço, localizado no Município de Brasília de Minas, Estado de Minas Gerais, precisamente na área pertencente ao Distrito de Fernão Dias, onde foram desenvolvidas ações ambientais para melhorias da mata de galeria que estava bastante comprometida por ações antrópicas.

Neste contexto o conceito de mata ciliar teve que ser recapitulado no seu significado científico e empírico para que todos os participantes o compreendessem a partir de um nivelamento necessário. Sendo assim, iniciou-se o debate fundamentado em Castro, (2012) 


\begin{abstract}
As Matas Ciliares são importantes por apresentarem um conjunto de funções ecológicas extremamente relevantes para a qualidade de vida, especialmente, das populações humanas locais e da bacia hidrográfica, sendo fundamentais para a conservação da diversidade de animais e plantas nativas da região, tanto terrestres como aquáticos. As Matas Ciliares influenciam na qualidade da água, na regulação do regime hídrico, na estabilização de margens do rio, na redução do assoreamento da calha do rio e são influenciadas pelas inundações, pelo aporte de nutrientes e pelos ecossistemas aquáticos que elas margeiam. (CASTRO, 2012, p. 07).
\end{abstract}

A função da mata ciliar é proteger os recursos hídricos, sendo amparada pelo Código Florestal Brasileiro, Lei $\mathrm{N}^{\mathrm{o}} 4.771 / 65$ onde considera as Matas Ciliares como Áreas de Preservação Permanente - (APPs), locais que apesar da proteção são alvo de ações indevidas do homem, culminando muitas vezes em sua extinção: ocupação agrícola, construção de barragens, mineração, dentre outros.

As ações de preservação das matas ciliares originaram-se especialmente na década de 1970 em todo o mundo, buscando garantir a recuperação e preservação das mesmas e simultaneamente promover o equilíbrio ambiental. A partir de práticas de conservação e manejo adequado dos solos, fatores que asseguram a proteção dos mananciais hídricos outros aspectos ambientais são estabelecidos, redução do assoreamento dos rios e aporte de poluentes, criação de corredores que favorecem o fluxo genes entre remanescentes florestais, produção de alimento e abrigo para a fauna. (CASTRO, 2012).

$\mathrm{Na}$ visita de campo, ficou evidente o desaparecimento de parte da mata ciliar concomitantemente extinção de fauna e flora, além da degradação dos solos. Observou-se presença de unidades de irrigação e os danos ambientais decorrentes de agricultura voltada para o comércio sem a devida fiscalização necessária.

Nas próximas partes será abordada a experiência ambiental na Educação Básica, com os discentes do sexto, sétimo, oitavo e nono ano do Ensino Fundamental, as particularidades metodológicas e os pormenores do trabalho de campo.

\title{
A ABORDAGEM DA EDUCAÇÃO AMBIENTAL NA ESCOLA BÁSICA
}

Segundo Dias (2004), a abordagem da Educação Ambiental nas escolas não deve ser conservadora, apresentando somente ensinamentos e conhecimentos que permeiam o uso consciente dos recursos naturais e à conservação dos ecossistemas, mas a educação direcionada para o meio ambiente, que provoque além de conhecimentos, mudanças de valores e uma visão ampla, que ultrapasse o conservadorismo. 
De acordo com Schinke, (1986)

Entre os vários aspectos negativos da atual educação ministrada no Brasil, ressalta o fato de ela não desenvolver no estudante os esquemas mentais que estabelecem a relação dialética das diferentes áreas de estudo entre si e também destas com a realidade social em que vivemos. $O$ estudo da ecologia, enquanto "ciência pura", de quase nada adianta se não relacionada com os demais campos da ciência, porque ela não leva necessariamente a uma visão globalizante, dinâmica e sistêmica das coisas, isto é, a uma visão "eco-política" (SCHINKE, 1986, p. 153).

Ressalta-se assim, a importância do diálogo interdisciplinar e a construção do conhecimento de maneira coletiva, fazendo com que o ensino seja partilhado não de forma adversária, mas como um possível caminho que permite ao indivíduo aprender e apreender a realidade na qual está inserido, aguçando a sensibilização ambiental e a cidadania.

Diante do pressuposto é possível observar que as questões ambientais vêm ganhando cada vez mais importância social, gerando muitos estudos que surgem a partir de diferentes fatores que visam à sistematização da sociedade. Desse modo, as escolas passaram a intensificar as discussões sobre os problemas do Meio Ambiente e suas diversas faces, intermediando diferentes práticas pedagógicas como meios auxiliadores e responsáveis na formação de cidadãos participantes na construção do mundo.

A Lei n 9.795, de 27 de abril de 1999, que institui a Política Nacional de Educação Ambiental, Art. $9^{\circ}$, aponta a necessidade da mesma ser trabalhada nas instituições de ensino públicas e privadas, sendo desenvolvidas em:

I - Educação básica:

a. Educação Infantil;

b. Ensino Fundamental

c. Ensino Médio

II - Educação Superior;

III - Educação Especial;

IV- Educação Profissional;

V - Educação para Jovens e Adultos.

A Educação Ambiental e suas diferentes faces deve permear todas as fases escolares, se desenvolvendo de maneira multidisciplinar, não como uma nova disciplina, mas se aliando a todas as habilidades do currículo escolar, sendo uma importante parceira na busca do saber integrado, tendo em vista o conhecimento além da fragmentação.

É possível perceber que a escola é espaço privilegiado para a inserção de atividades que propiciem a reflexão da interação interdisciplinar da Educação Ambiental, a partir de 
ações orientadas em processos de participação que induzam à autoconfiança, às atitudes positivas e ao comprometimento pessoal com a proteção ambiental, executados de modo multidisciplinar.

A Educação e o Meio Ambiente estão atrelados por um conjunto de práticas que conduzem os indivíduos a refletirem o espaço em que vivem. Por meio da Educação Ambiental, os docentes transmitem ideias de sensibilização, levantando informações e trocas de conhecimentos, construindo gradativamente um olhar crítico.

$\mathrm{Na}$ Educação Básica, durante o processo ensino/aprendizagem na perspectiva da educação ambiental são encontrados inúmeros desafios e dificuldades. Apesar de os docentes estarem inteirados a respeito das responsabilidades e das temáticas a eles designados, observase diversos obstáculos quanto à aplicação de conteúdos referentes ao tema, tendo em vista que engloba diferentes assuntos, particularidades e peculiaridades, o que não é oferecido aos docentes nas capacitações e nem mesmo estão incluídos nos planos de aula como temáticas transversais. (SCHINKE,1986).

Outro empecilho encontrado pelos professores é a falta de material didático onde, na maioria das vezes os livros fornecidos não possuem conteúdos diretamente relacionados a educação ambiental, sendo preciso a utilização de outras metodologias pedagógicas, o que não é disponibilizado pelas instituições de ensino, tornando o trabalho, assim como o aprendizado mais dificultoso. Essa premissa está também interligada aos parcos recursos financeiros disponibilizados pelo Estado às Escolas de Educação Básica, devido à alta demanda dos mesmos no Brasil.

Algumas vezes o material didático oferece ainda conteúdos tendenciosos, abordando a Educação Ambiental, sobretudo os problemas ambientais como algo possível, mas não concreto o que induz os discentes a transmissão do assunto trabalhado de uma maneira estremada e segmentada, os apresentando um conhecimento pronto e acabado, fazendo com que a Educação Ambiental seja desenvolvida nas escolas somente como projetos extracurriculares, sem sequência e contexto, fragmentado e desarticulado, não havendo o conhecimento por meio da dialética ou de uma metodologia pedagógica interdisciplinar. (DIAS, 2004).

A apresentação do conteúdo da maneira citada acarreta ainda mais problemas pois, as questões ambientais são apresentadas aos estudantes de maneira errônea e confusa, instigando-os a pensar que é necessário apenas preservar os recursos naturais, sem se levar em conta por exemplo, as políticas públicas que lhes oferecem meios conscientes do uso destes recursos. Sendo assim, os discentes acabam sendo apenas ouvintes, quando deveriam ser 
agentes participantes e colaboradores com o Meio no qual estão inseridos, gerando a prática a partir da teoria, desenvolvendo atividades e projetos que exerçam a sensibilização a partir da realidade vivida. (SCHINKE,1986).

Neste direcionamento, na próxima parte será descrito a respeito da relevância da prática de campo relacionada diretamente com a interdisciplinaridade da Educação Ambiental na Educação Básica no município de Brasília de Minas, no Estado de Minas Gerais, na Sub Bacia do Rio São Lourenço, tributário do Rio Riachão que está localizado a margem direita do rio Pacuí em seu baixo curso, banhando os municípios de Montes Claros, Coração de Jesus, Mirabela e Brasília de Minas.

\section{PRÁTICAS DE ENSINO E CAMPO EM CONTEXTOS SIMULTÂNEOS}

A Educação e o Meio Ambiente estão ligados por um conjunto de práticas que conduzem o estudante a refletir no ambiente em que vive. Embora muitas vezes encontrem dificuldades de trabalhar com uma didática flexível, é através da Educação Ambiental que os docentes conseguem passar a ideia de preservação e sensibilização, propondo assim, dinâmicas cartográficas e pesquisas sobre a temática com o intuito de levantar informações sobre os conhecimentos já existentes e promover debates em que os discentes possam trocar ideias e construir um olhar crítico.

Quando se é transmitido problemas ambientais em noticiários de jornais, revistas, $\mathrm{TV}$, rádio, internet e outros; imagina-se algo distante do que presenciamos todos os dias, entretanto, muitas vezes são fatos frequentes do dia a dia, que passam desapercebidos.

De acordo com Lima (2009)

Essa dissociação entre os aspectos biológicos/ecológicos e os aspectos políticos e sociais da crise ambiental é um dos argumentos centrais da Educação Ambiental, pois criticava que, partindo de outro diagnóstico, destacava o caráter estrutural e civilizatório da crise ambiental e a necessidade de respostas transformadoras tanto políticas quanto éticas da questão. Segundo sua compreensão, os impactos ecológicos eram apenas os efeitos de causas muito mais profundas que indicavam a degeneração de todo um modelo civilizatório baseado em opções políticas e valorativas predatórias e nocivas à vida social e natural (LIMA, 2009, p. 153).

Uma das alternativas para a inclusão da temática ambiental no meio escolar é "a aprendizagem em forma de projetos". Segundo Capra (2003), essa é uma proposta alinhada com o novo entendimento do processo de aprendizagem que sugere a necessidade de 
estratégias de ensino mais adequadas e torna evidente, a importância de um currículo integrado que valorize o conhecimento contextual, no qual as várias disciplinas sejam vistas como recursos a serviço de um objeto central. Este também pode ser entendido como um tema transversal que permeia as outras disciplinas já constituídas e consegue trazer para a realidade escolar o estudo de problemas do cotidiano.

Sendo assim, surgiu a ideia do Projeto Novos Talentos em parceria com o Programa Institucional de Bolsas de Iniciação à Docência - (PIBID) da Universidade Estadual de Montes Claros - (UNIMONTES), a Empresa de Assistência Técnica e Extensão Rural do Estado de Minas Gerais -(EMATER), além dos discentes da Escola Municipal Joaquim Cardoso ${ }^{4}$,para realizar o plantio de mudas orientado, visando promover o reflorestamento de parte da nascente do Rio São Lourenço, no Município de Brasília de Minas - Minas Gerais, precisamente na área pertencente ao Distrito de Fernão Dias.

O Mapa 1 evidência a Bacia do Rio Riachão e localizada o Rio São Lourenço no seu baixo curso, além de apontar imagens de satélite com vistas parciais do Distrito de Fernão Dias e da Mata ciliar em torno do Rio São Lourenço, onde é possível localizar a presença de pivô central próximo à referida mata e rio.

${ }^{4} \mathrm{O}$ PIBID/UNIMONTES foi convidado para participar do referido trabalho de campo por intermédio da coordenação do Projeto Novos Talentos. Esclarecemos que toda a gestão do Encontro foi organizada pela EMATER, IEF e Coordenação do Projeto citado que reuniu antecipadamente com a professora coordenadora e acadêmicos do PIBID para esclarecer todo o percurso do trabalho de campo. Portanto, o termo de autorização para participação dos discentes foi de inteira responsabilidade da direção da escola convidada. O PIDID GEOGRAFIA/UNIMONTES não teve acesso ao referido documento. 
Mapa 1: Rio São Lourenço - Distrito de Fernão Dias/ Brasília de Minas - Minas Gerais.

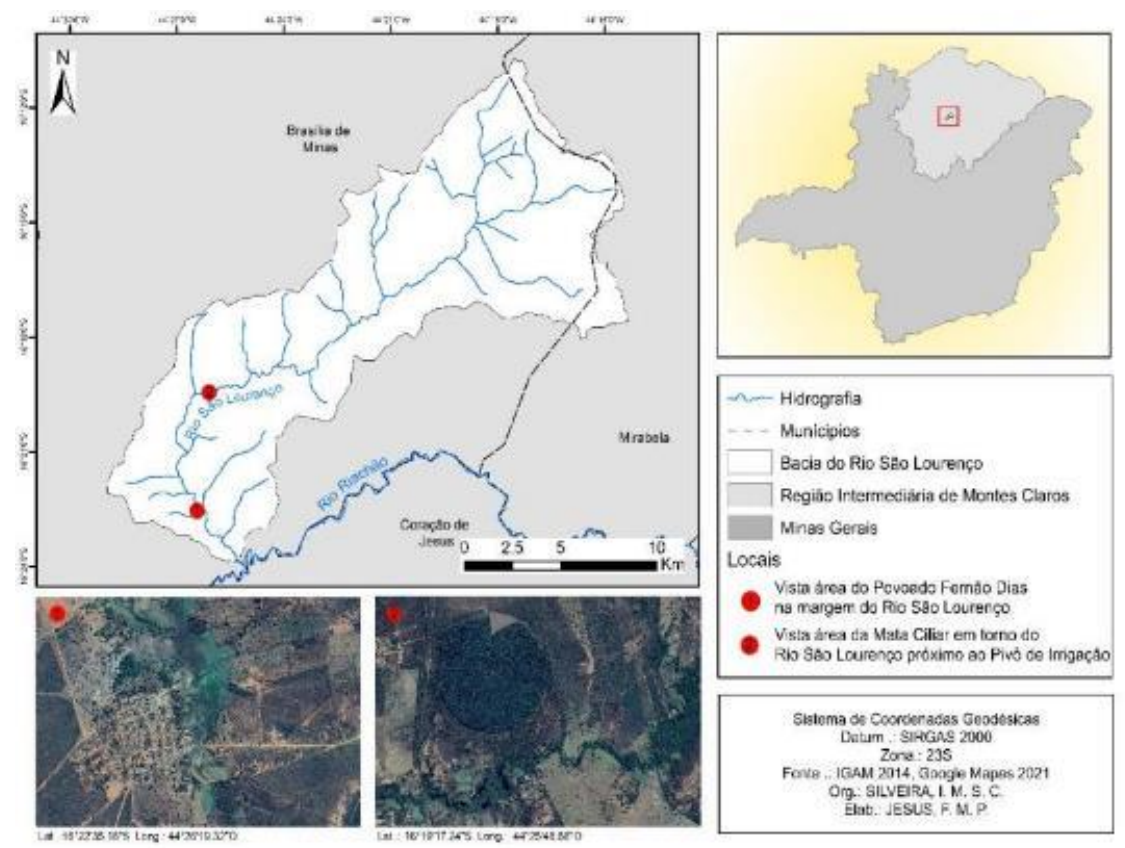

Fonte: Silveira (2021)

Os passos metodológicos adotados no processo de reflorestamento estão descritos em suas etapas:

- Revisão Bibliográfica, a fim de estabelecer uma maior inteiração sobre o assunto. Conforme Noronha e Ferreira (2000) torna-se necessário analisar as produções bibliográficas anteriores relativas à temática em um espaço temporal, pois balisará o conteúdo a ser pesquisado em tópicos específicos, verificando os métodos e ideias adotadas quanto as partes e o todo do objeto em um trabalho enriquecedor.

- Reuniões de planejamento elaboradas pelos acadêmicos do PIBID do Subprojeto Geografia: Educação para à Promoção da Saúde inserido na Escola Estadual Antônio Canela em Montes Claros. Segundo Fuks et al., (2002) este passo é muito importante como ferramenta de comunicação pois, durante todo o percurso da pesquisa os envolvidos dispõem de um nivelamento das principais ideias compartilhadas, além de maior consolidação para as tomadas de decisões. O planejamento, com certeza, desenvolverá e valorizará o trabalho dos pesquisadores participantes. 
Educação Ambiental e suas Práticas como exercício da cidadania na Escola Básica

Iara Maria Soares Costa da Silveira; Túlio de Oliveira Ruas; Nayara Ferreira Elias

Quadro 01: Cronograma de Planejamento do PIBID - Subprojeto Geografia Educação para à Promoção da Saúde.

\begin{tabular}{|l|l|}
\hline \multicolumn{1}{|c|}{ Mês/Ano } & \multicolumn{1}{c|}{ Tipo de Reunião } \\
\hline Fevereiro/2015 & $\begin{array}{l}\text { Reunião da Coordenação do Projeto Novos Talentos e } \\
\text { Coordenação do PIBID - Subprojeto: Geografia: } \\
\text { Educação para à Promoção da Saúde. }\end{array}$ \\
\hline Março/2015 (Primeira quinzena) & $\begin{array}{l}\text { Reunião Expositiva para conhecimento dos acadêmicos } \\
\text { do PIBID e Projetos Novos Talentos, juntamente com as } \\
\text { coordenadoras, para esclarecimentos acerca do Projeto. }\end{array}$ \\
\hline Março/2015 (Segunda quinzena) & $\begin{array}{l}\text { Reunião conjunta para orientações gerais do roteiro e do } \\
\text { processo de plantio. }\end{array}$ \\
\hline Abril/2015 (Primeira quinzena) & Execução do Trabalho de Campo. \\
\hline Abril/2015 (Segunda quinzena) & $\begin{array}{l}\text { Reunião do PIBID - Subprojeto: Geografia: Educação } \\
\text { para à Promoção da Saúde para considerações e } \\
\text { avaliação do Projeto. }\end{array}$ \\
\hline
\end{tabular}

Fonte: Arquivo PIBID (2015)

Foto 1: Reunião Parcial para Planejamento das atividades.

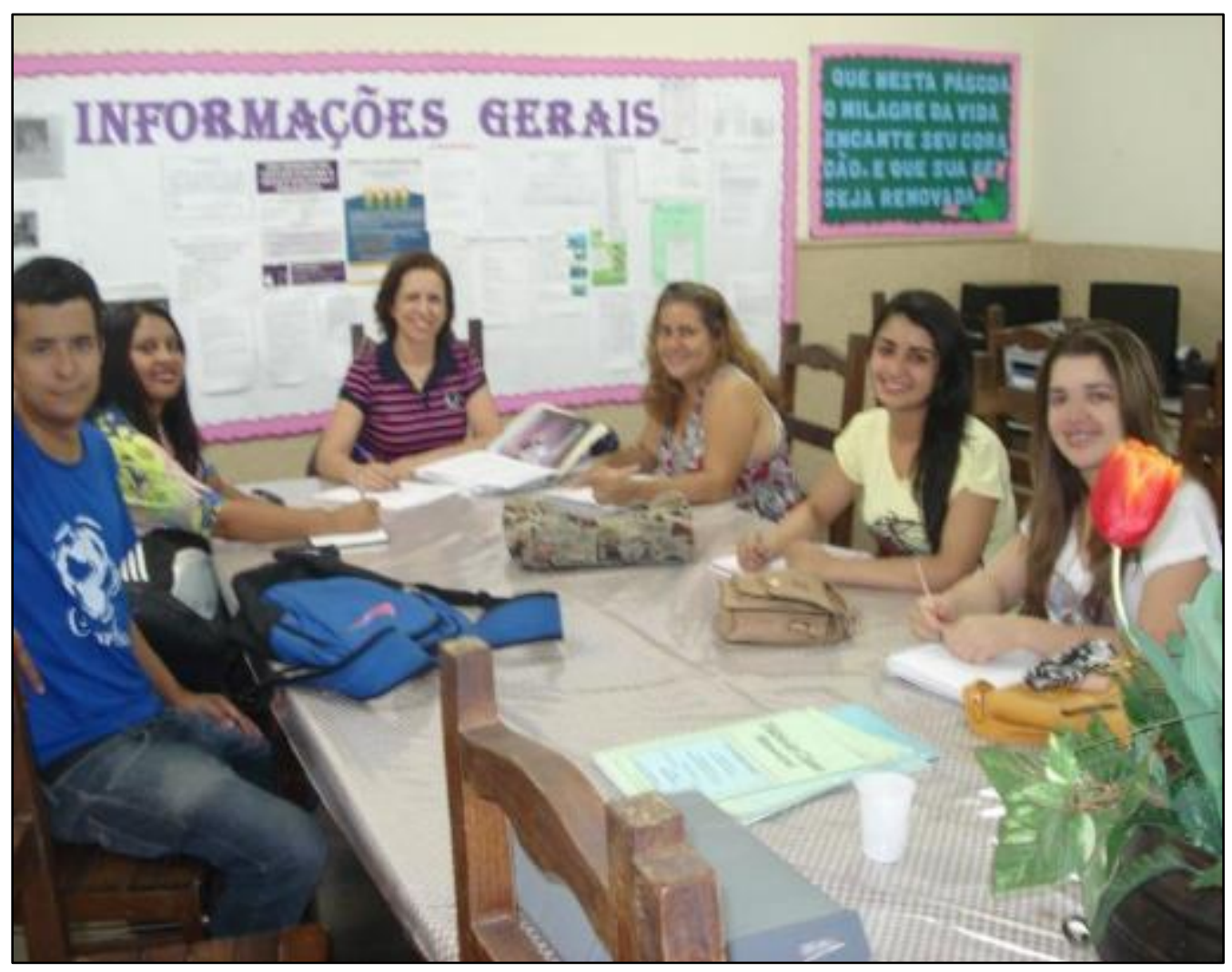

Fonte:Arquivo PIBID (2015)

- Formação Técnica realizada pela EMATER com a participação dos moradores locais, alunos da Comunidade Rural próxima ao Rio São Lourenço e representantes do PIBID em Geografia - UNIMONTES. Esta formação possibilitou a organização de ideias críticas e reais da demanda solicitada pelo projeto socioambiental, pois cada ação necessitou de diagnóstico que viabilizassem as necessidades do espaço e da comunidade, 
Educação Ambiental e suas Práticas como exercício da cidadania na Escola Básica

Iara Maria Soares Costa da Silveira; Túlio de Oliveira Ruas; Nayara Ferreira Elias

além de novos caminhos que efetivaram o desenvolvimento do projeto. (EMATER -RO, 2002)

Foto 2: Formação Técnica em campo.

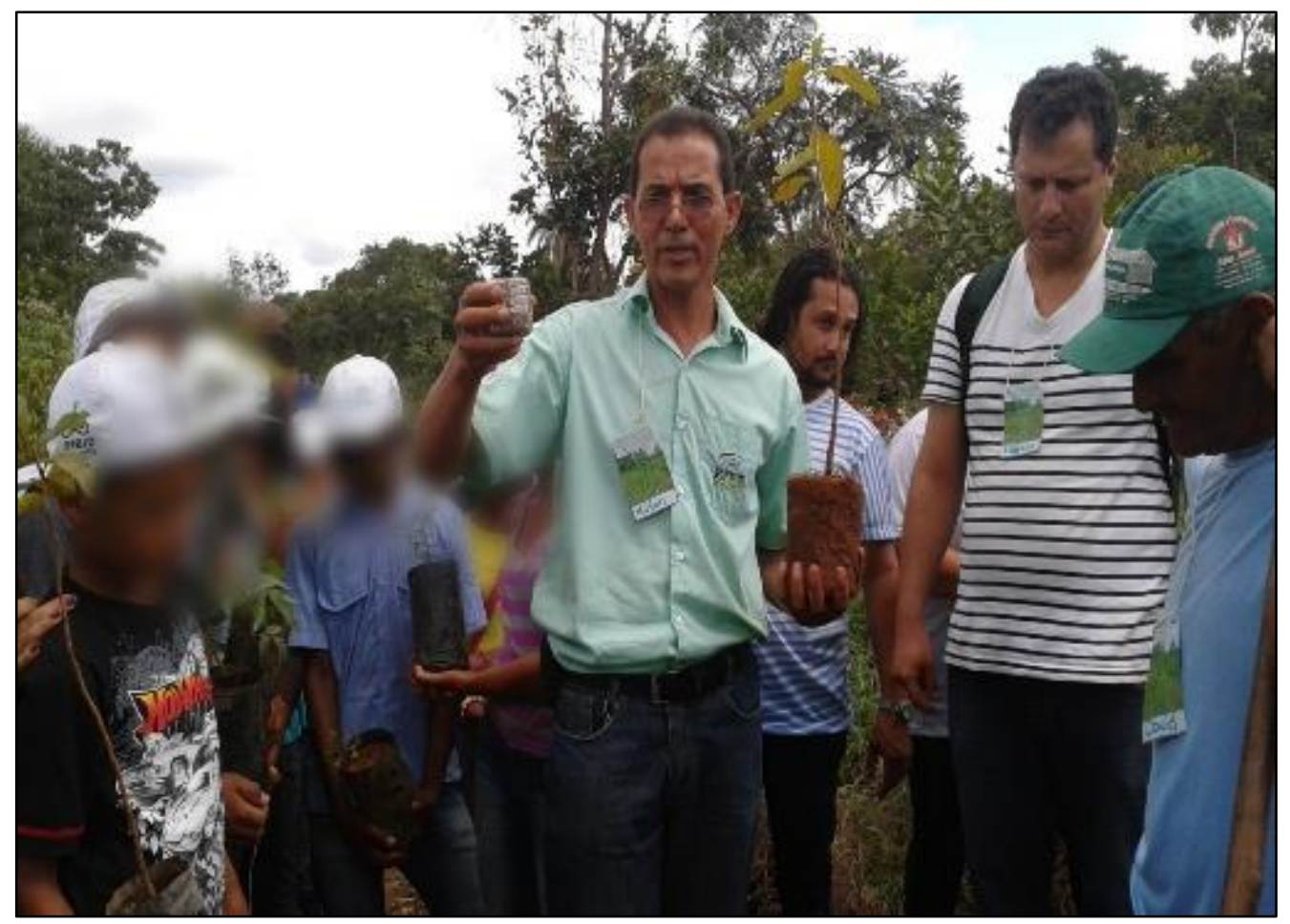

Fonte: Elias (2015)

Foto 3: Formação Técnica em campo

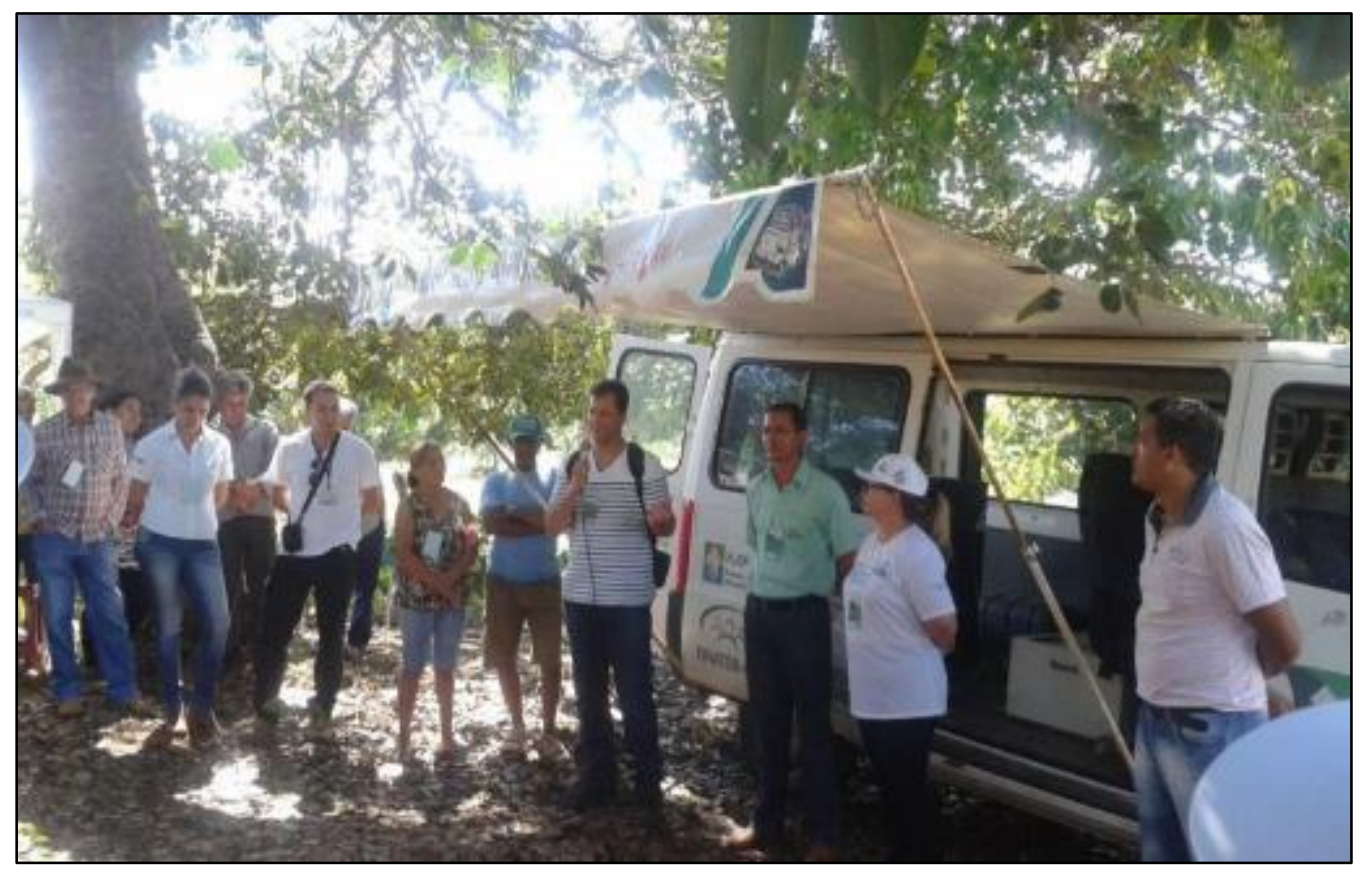

Fonte: Elias (2015) 
- Limpeza da área de reflorestamento de forma correta e recolhimento de detritos diversos, sem agressão do solo e ambiente local. A limpeza da área para o plantio de mudas passa primeiramente pela roçagem sem remoção do solo para a eliminação das espécies competidoras. Conforme Ferreira Et. al. (2019) nas unidades de conservação é preciso desenvolver as espécies vegetais a partir da extinção de classes invasoras, por meio de planos de manejo sustentável como a conservação de produtos agroflorestais que posteriormente produzirá benefícios tanto para a natureza quanto para a comunidade local envolvida.

Foto 4: Limpeza do Solo.

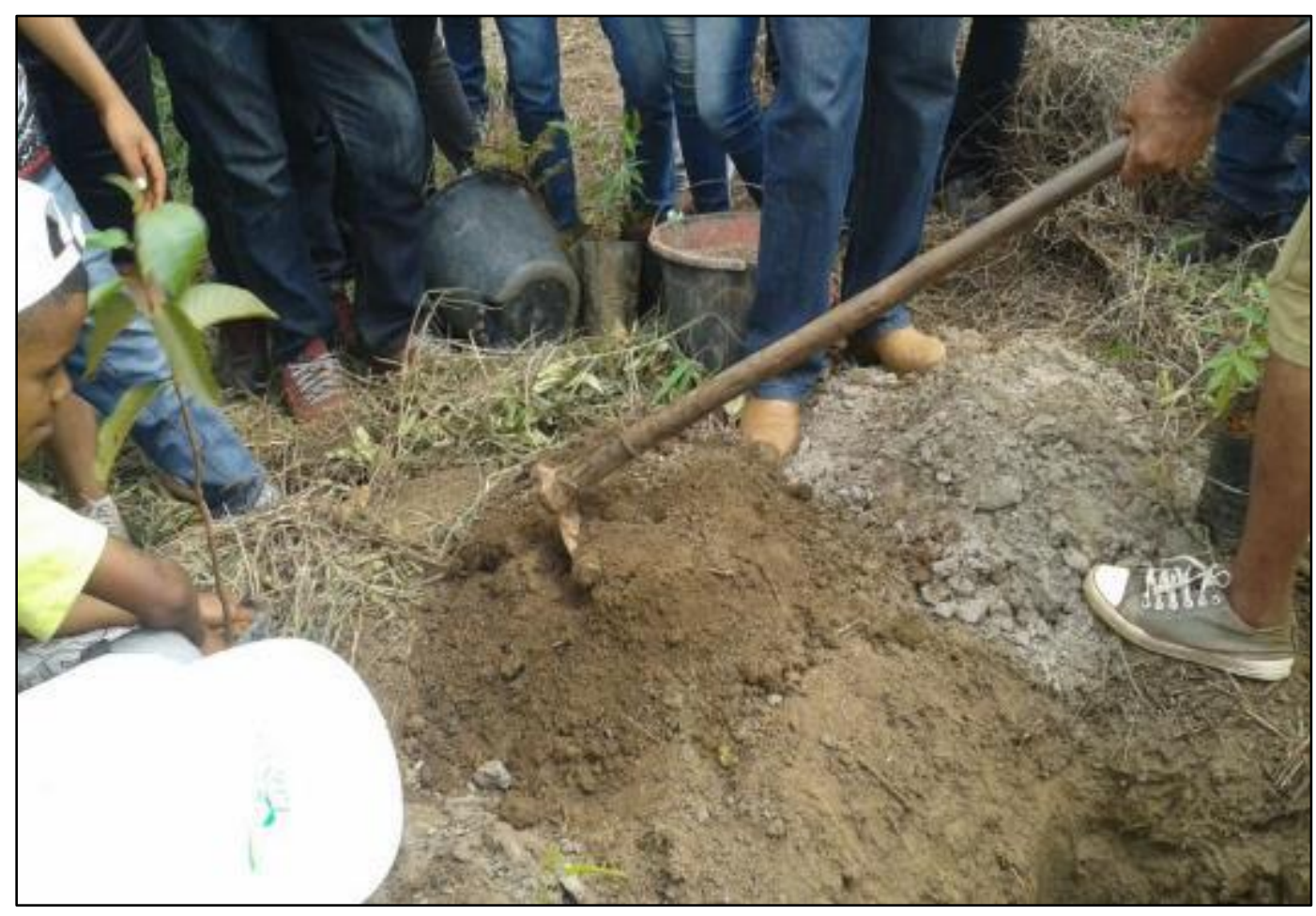

Fonte: Elias, (2015)

- Produção e seleção de mudas de espécies nativas a serem plantadas, concedidas pelo Instituto Estadual de Florestas - IEF. Segundo o Cadernos da Mata Ciliar é preciso avaliar a interferência da vegetação no consumo de água das nascentes, pois os lençóis freáticos possuem diferentes profundidades e influenciam no raio de delimitação da área de preservação permanente (SECRETARIA DO MEIO AMBIENTE, 2009) 
Foto 5: Mudas Selecionas concedidas pelo IEF.

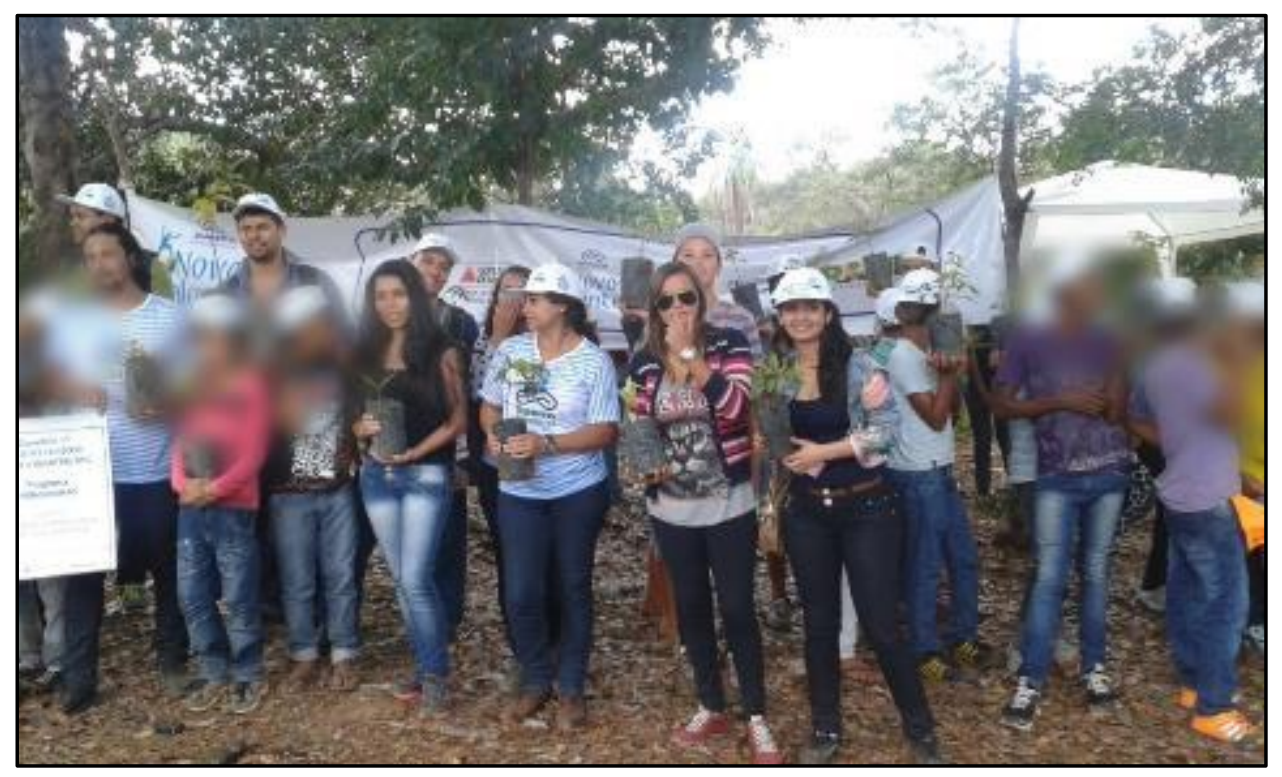

Fonte: Elias (2015)

- Plantio de mudas em seus locais definitivos, feito pela comunidade local, acadêmicos do PIBID e alunos da Educação Básica, dentro das tecnologias aceitáveis para o plantio. Ao selecionar as espécies a serem plantadas a equipe da EMATER agrupou-as em blocos heterogêneos e distribuiu cada um de acordo com o local onde seriam fixadas, dentre elas foram plantadas Ourateaspectabilis (folha-de-serra), Handroanthus (Ipê), Dimorphandramollis (faveiro), Byrsonima intermedia (murici-do-cerrado), Aspidosperma tomentosum (peroba-do-cerrado), Annonacoricea (araticum ou pindaíba), entre outras. As equipes foram formadas equitativamente incluindo membros das instituições representadas de forma espontânea e participativa. (LORENZI, 2008)

Foto 6: A caminho da área de plantio.

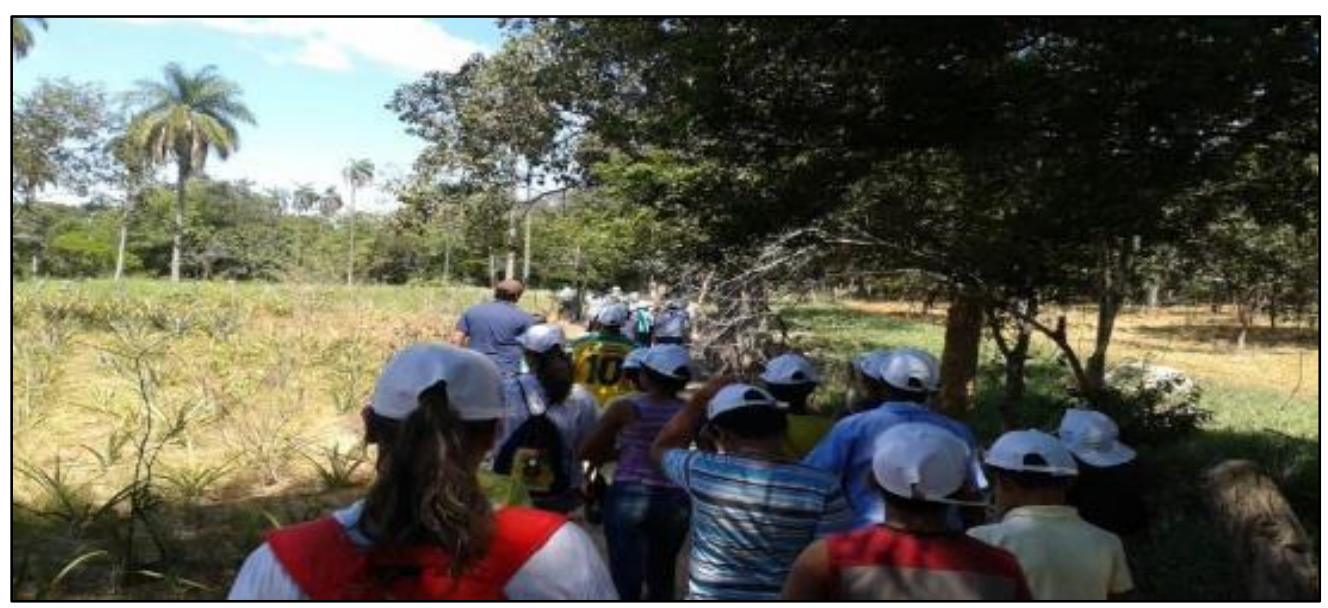

Fonte: Elias (2015) 
Educação Ambiental e suas Práticas como exercício da cidadania na Escola Básica

Iara Maria Soares Costa da Silveira; Túlio de Oliveira Ruas; Nayara Ferreira Elias

Foto 7: Início do plantio de mudas.

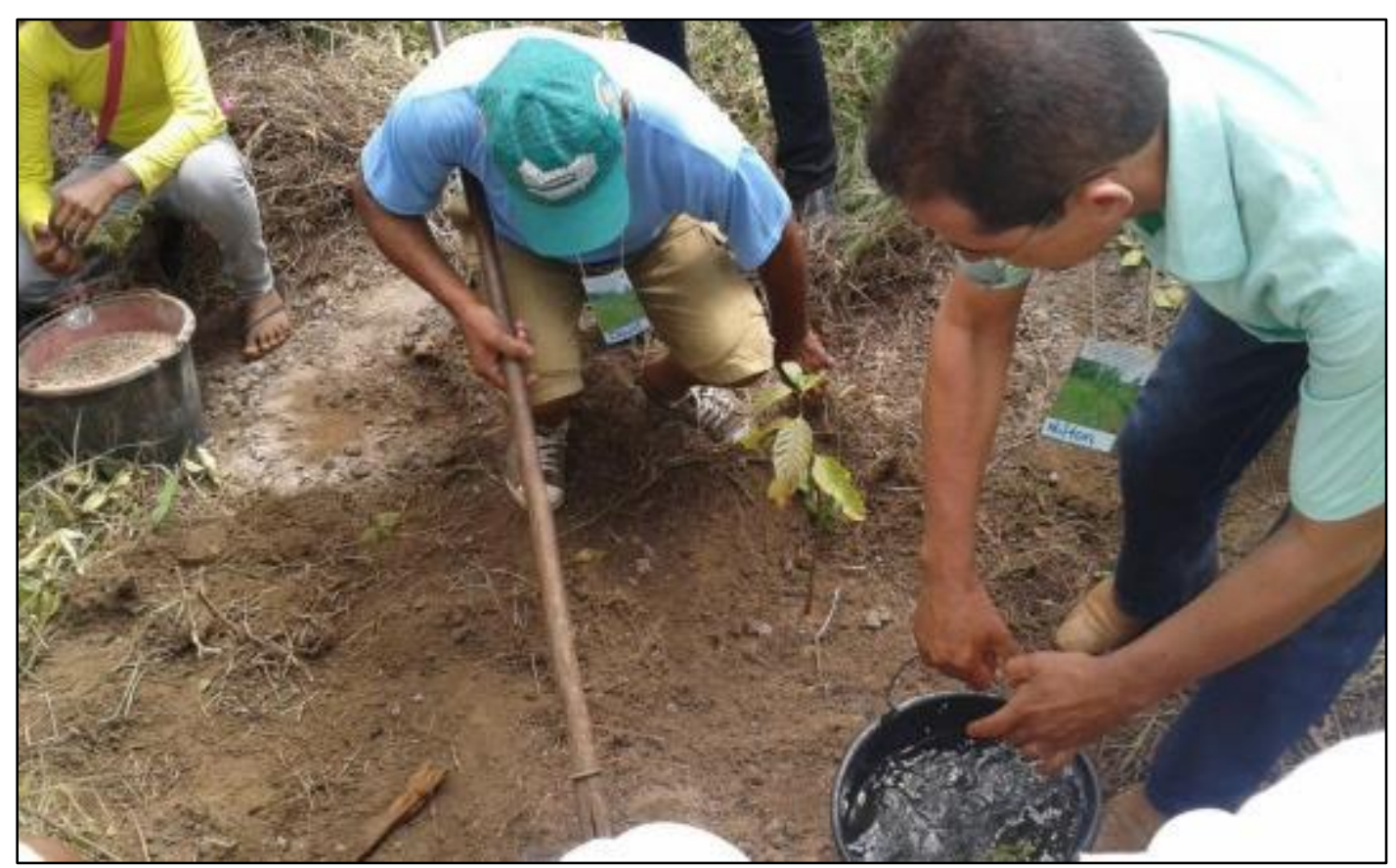

Fonte: Elias (2015)

Foto 8: Plantio de mudas.

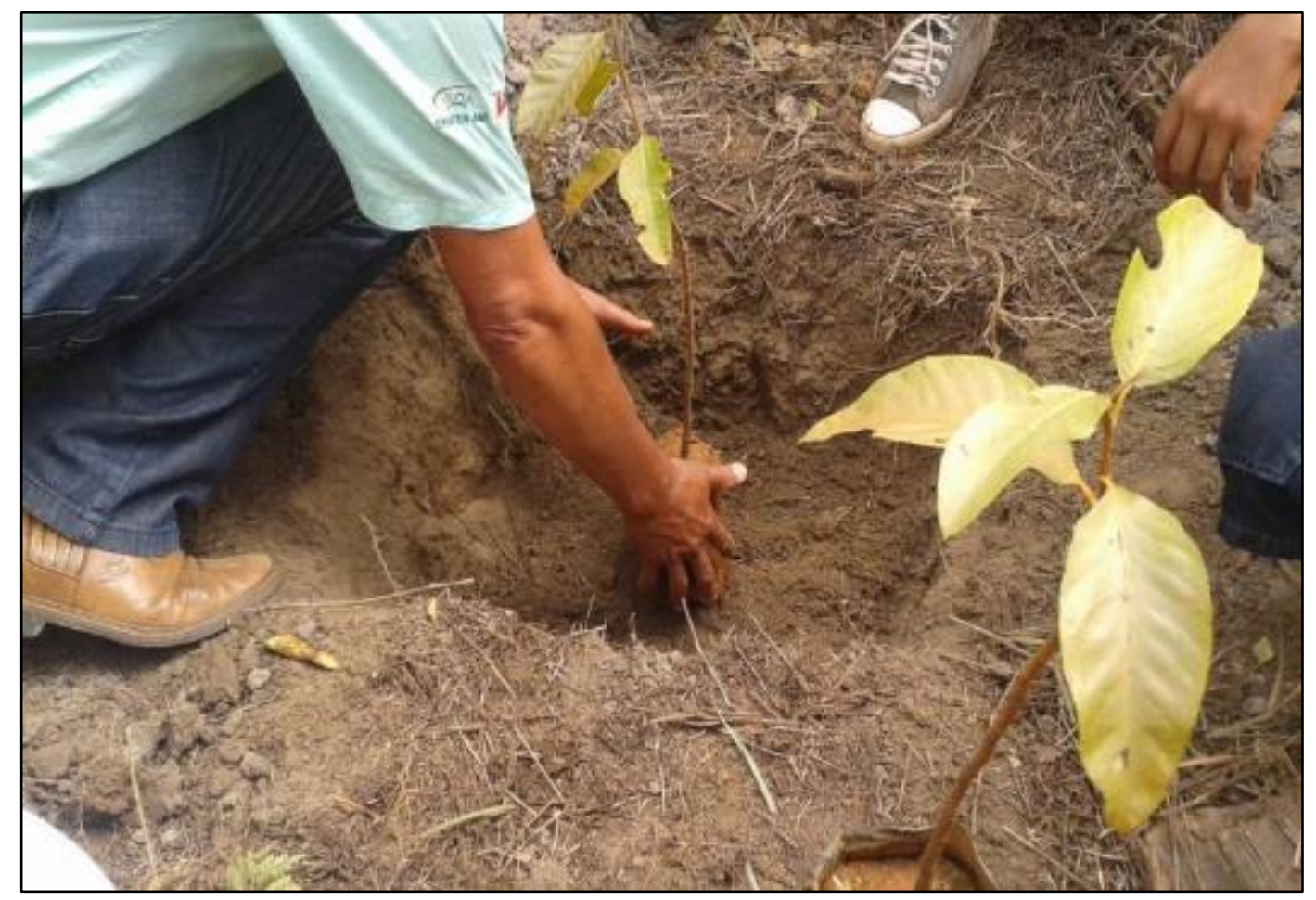

Fonte: Elias (2015) 
Foto 9: Nascente beneficiada.

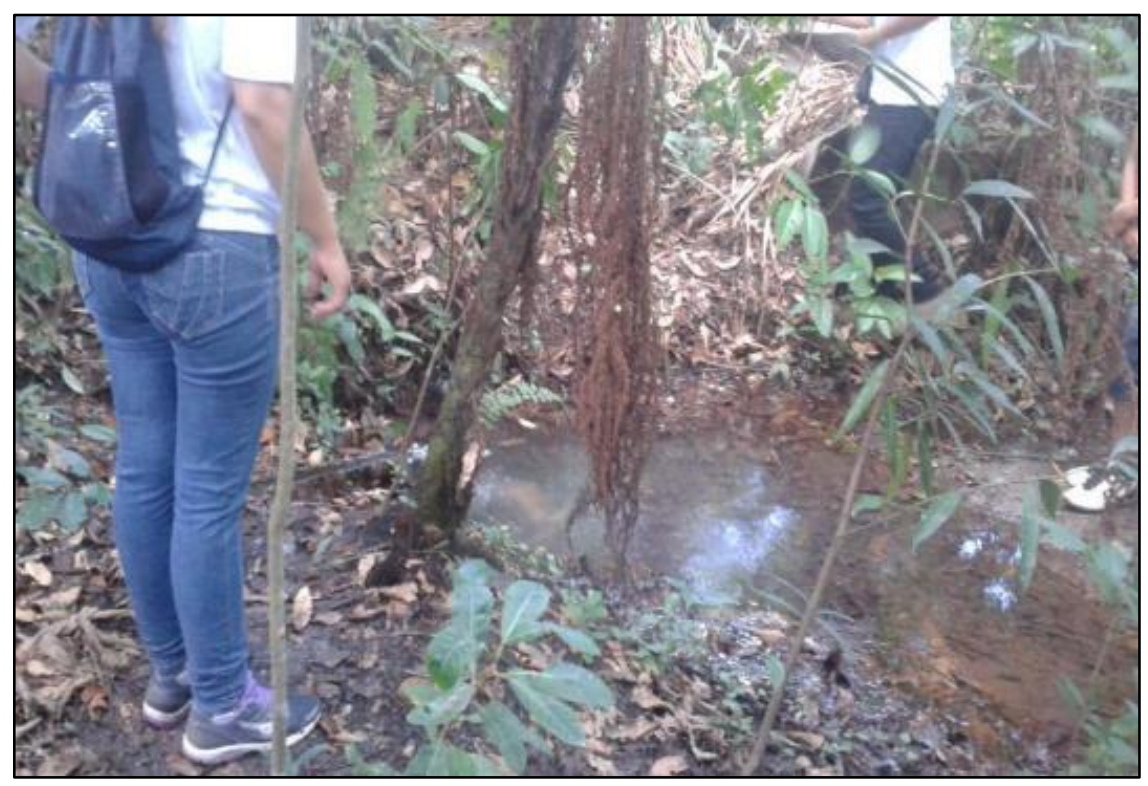

Fonte: Elias (2015)

O plantio de mudas, ocorrido em abril de 2015 obteve resultados positivos para a Área de Preservação Permanente - APP, onde atualmente (2021) encontra-se, além de reflorestado em suas nascentes também mais arborizado em outros pontos, trazendo inúmeros benefícios para a fauna, flora e moradores locais, que continuam se esforçando diariamente na preservação e luta para a permanência, sobretudo, da mata ciliar na nascente do Rio São Lourenço. Segundo os gestores após o plantio os moradores mais próximos ao local e interessados pela preservação da Mata Ciliar ficaram com a responsabilidade de acompanhar o crescimento das espécies, bem como o cuidado e a reposição das mesmas.

Salienta-se ainda que o Projeto foi de extrema importância para os agentes participantes, acadêmicos do PIBID e alunos da Educação Básica, apontando que é possível, além de indicar problemas ambientais, buscar melhorias e tornar o olhar sensível para os mesmos, ocupando assim o espaço de cidadãos inteirados com o Meio o qual estão inseridos, contribuindo na construção de um mundo melhor e mais saudável.

A prática do aprendizado em Educação Ambiental foi singular, pois a interação com os aspectos teóricos e técnicos aconteceu de forma espontânea, liberta e humanizada. A troca de conhecimentos a partir de abordagens simples transcorreu de maneira organizada e gradativa, respeitando o ponto de vista dos participantes e o espaço do outro.

Projetos como este são importantes para acelerar a formação de novas posturas dos participantes, especialmente dos estudantes da Educação Básica em relação aos conteúdos tratados na Educação Ambiental, numa prática educativa voltada para a capacitação e 
estímulo dos participantes às novas propostas de um estilo de vida que favoreça um modelo sustentável.

\section{CONSIDERAÇÕES FINAIS}

A Educação Ambiental é essencial para sensibilização de uma sociedade, e abordar o tema em sala de aula é de extrema importância, pois os discentes precisam entender as causas e efeitos dos problemas ambientais que acontecem em seu próprio cotidiano.

A sensibilização é o ponto de partida a ser trabalhado com os alunos da Escola Municipal Joaquim Cardoso para que os mesmos possam detectar quais os problemas estão presentes no Meio em que vivem e se os mesmos e seus familiares podem ser os atores desses acontecimentos, que destroem o meio ambiente em todos os seus aspectos, assim como os agentes restauradores e cuidadores deste Meio.

Quando discutida a temática ambiental com os estudantes, busca-se um esclarecimento por parte dos mesmos sobre o Meio Ambiente. É preciso trabalhar a partir da realidade de cada um, a visão social desse cidadão e como esse indivíduo percebe o espaço e ambientes abrangentes em que se está inserido. Dias (2004) afirma que a Educação Ambiental busca proporcionar nas pessoas uma peculiaridade no convívio e manuseio crítico com o Meio Ambiente local, reportando conhecimentos, valores e ações para o mundo global. Nesta premissa, poderão desenvolver atitudes que lhes possibilitem construir uma consciência dos valores ambientais em função da melhoria da qualidade de vida do planeta, especialmente contendo ações que minimizem as ações antrópicas sobre o Espaço.

Essa visão em que os discentes devem identificar qual sua parcela de responsabilidade sobre o meio ambiente é de suma importância no estabelecimento de atitudes conscientes e ações coletivas para a melhora do Meio em que vivem, trabalhando assim uma relação escola e comunidade.

É de devida importância que os educandos participem da identificação dos problemas ambientais, para que possam também pensar possíveis soluções para estes que estão a sua volta. A Educação Ambiental em um dos seus objetivos propõe que cada indivíduo possa assumir o papel de elemento central da resolução de problemas que envolvem o espaço que os cerca, como agentes transformadores por meio das atitudes praticadas.

O trabalho de campo desenvolvido buscou consolidar os conhecimentos, valores e atitudes do cidadão plenamente consciente dos deveres na preservação do Meio. Observou-se o envolvimento e o compromisso dos mesmos nas etapas desenvolvidas, especialmente para 
os pibidianos que verificaram que a prática de campo é imprescindível na relação com a assimilação dos conteúdos trabalhados.

O futuro da sociedade depende da consciência que o ser humano tem em se relacionar com a natureza, sendo assim, os alunos da Educação Básica se tornam um público de grande importância, pois nessa faixa etária estão construindo uma visão crítica sobre suas atitudes e ações.

Para melhor conhecer o ambiente em que vive, o ser humano precisa ser ecologicamente alfabetizado. Quanto à alfabetização ecológica, Capra (1996) afirma que ser ecologicamente alfabetizado é compreender as bases da organização dos grupos que habitam os diversos ecossistemas, buscando formar gradativamente uma sociedade com princípios sustentáveis.

Entender o lugar em que se vive é relevante no contexto de mudanças ambientais por parte dos discentes, que se constituirão como os futuros cidadãos críticos e sensíveis as problemáticas ao seu entorno. A Escola como local de disseminação do conhecimento não poderá se furtar à sua realidade e responsabilidade na propagação dos conteúdos ministrados no contexto da Educação Básica.

\section{REFERÊNCIAS}

ATANASIO, Claudia Mira; GANDOLFI, Sergius; RODRIGUES, Ricardo Ribeiro. Manual de Reflorestamento Ambiental. São Paulo: Secretaria do Meio Ambiente, 2006.

BRASIL, Código Florestal Brasileiro, Lei $\mathrm{N}^{\mathrm{o}}$ 4.771/65. Disponível em https://cetesb.sp.gov.br/licenciamento/documentos/1965_Lei_Fed_4771.pdf. Acesso em: 15. dez. 2020.

CASTRO, Dilton. Práticas para restauração da mata ciliar. / Org. Dilton de Castro; Ricardo Silva Pereira Mello e Gabriel CollaresPoester. -- Porto Alegre: Catarse - Coletivo de Comunicação, 2012.

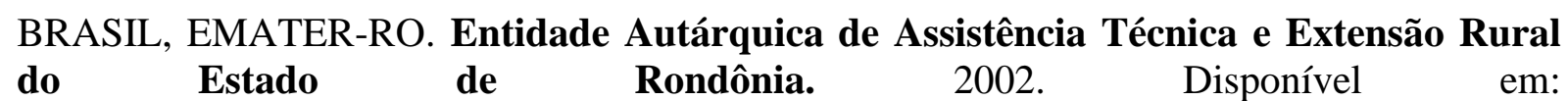
http://www.emater.ro.gov.br/ematerro/2018/12/20/anater-promove-a-capacitacao-deextensionistas-da-emater-ro-em-elaboracao-e-execucao-de-projetos-sociais-para-o-terceirosetor/ Acesso em 20 jan.2021.

FERREIRA, Robson Soares. Et al. Áreas degradadas: Técnicas de Reflorestamento Ambiental. Revista Científica Multidisciplinar Núcleo do Conhecimento. Ano 04, Ed. 06, Vol. 11, p. 71-84, 2019. 
FONSECA, J. J. S. Metodologia da pesquisa científica. Fortaleza: UEC, 2002. Apostila. Disponível em http://www.ia.ufrrj.br/ppgea/conteudo/conteudo-20121/1SF/Sandra/apostilaMetodologia.pdf. Acesso em: 18dez. 2020.

FUKS, H.; RAPOSO, A.B.; GEROSA, M. A. Engenharia de Groupware: Desenvolvimento de Aplicações Colaborativas. XXI Jornada de Atualização em Informática, Anais do XXII Congresso da Sociedade Brasileira de Computação, V2, Cap. 3, 2002.

GOMES, Marco Antônio Ferreira.Água: sem ela seremos o planeta Marte de amanhã. Disponível em: http://webmail.cnpma.embrapa.br/down_hp/464.pdf. Acesso em: 15 dez. 2020.

KAGEYAMA, P. Y. et al. Recuperação de Áreas Ciliares. Editora da Universidade de São Paulo. Fapesp. São Paulo. 2000.

KAGEYAMA, P. Y. et al. Restauração da Mata Ciliar - Manual para recuperação de áreas ciliares e microbacias. Projeto PlanáguaSemads/GTZ. São Paulo. 2002.

LORENZI, H. 1949.Árvores Brasileiras: manual de identificação e cultivo de plantas arbóreas nativas do Brasil. Vol 1. 5. Ed. Nova Odessa-SP: Instituto Plantarum.2008.

NORONHA, Daisy Pires; FERREIRA, Sueli Mara S. P. Revisões de literatura. In: CAMPELLO, Bernadete Santos; CONDÓN, Beatriz Valadares; KREMER, Jeannette Marguerite (orgs.) Fontes de informação para pesquisadores e profissionais. Belo Horizonte: UFMG, 2000.

SCHINKE, Gert. Ecologia Política. Santa Maria: Tchê! Editora, 1986.

SMA. Secretaria de Meio Ambiente do Estado de São Paulo. Cadernos da Mata Ciliar, 2009. São Paulo: SEMA/SP. V.2. p.01-36, 2019. Disponível em: http://arquivos.ambiente.sp.gov.br/municipioverdeazul/2013/05/Cadernos-de-Mata-Ciliar1_Preserva\%C3\%A7\%C3\%A30-e-recupera\%C3\%A7\%C3\%A3o-de-nascentes_2004.pdf. Acesso em: 15. dez. 2020.

SMA. Secretaria de Meio Ambiente do Estado de São Paulo. Projeto de Recuperação de Matas Ciliares - Nota Conceitual. São Paulo: SMA, 2004.

Artigo recebido em: 04 de fevereiro de 2021. Artigo aceito em: 26 de março de 2021. Artigo publicado em: 26 de março de 2021. 